\title{
Forecasting Agricultural Production: A Chaotic Dynamic Approach ${ }^{1}$
}

\author{
Bünyamin Demir², Nesrin Alptekin ${ }^{3}$, Yılmaz Kılıçaslan ${ }^{4,5}$, Mehmet Ergen², Nilgün \\ Çağlarırmak Uslu ${ }^{5}$
}

Received: $20 / 11 / 2014$

Revised: 03/01/2015

Accepted:07/02/2015

\begin{abstract}
The aim of this study is to examine the existence of chaotic structure in agricultural production in Turkey by using "Chaotic Dynamic Analysis (CDA)" and to provide an accurate forecast of agricultural production. The data of wheat, barley and rice production in Turkey obtained from Turkish Statistical Institute (TURKSTAT) covers the period of 1991 to 2009. Our analysis shows that the supply of the selected agricultural products has a chaotic structure. The dynamic system constructed in this study predicted the supply of the year 2010 with a margin error of $0.5,5$, and 2.5 percentages for wheat, barley, and rice respectively. This study is the first attempt using CDA to forecast future agricultural product supply in Turkey. The findings of this study will help to produce effective policies to prevent supply disequilibrium, and excess price fluctuations.
\end{abstract}

Keywords: Chaotic dynamic analysis, lyapunov exponent, deterministic nonlinear prediction, agriculture, Turkey.

JEL Codes: C60, C61, Q11

\footnotetext{
${ }^{1}$ This work was supported by TUBITAK (The Scientific and Technological Research Council of Turkey) as a part of 109K129 research project.

${ }^{2}$ Department of Mathematics, Anadolu University, Eskisehir, Turkey.

${ }^{3}$ Department of Management, Anadolu University, Eskisehir, Turkey.

${ }^{4}$ Corresponding Author, e-mail: ykilicaslan@anadolu.edu.tr

5 Department of Economics, Anadolu University, Eskisehir, Turkey.
} 


\section{Introduction}

Changes in the Earth's ecological system due to climate change and the increase in the demand for agricultural products in recent years have triggered disequilibrium tendencies in the markets for agricultural products. One way to eliminate disequilibrium in agricultural markets is to increase productivity and efficiency in agricultural sector. The second, as important as agricultural productivity, is to be able to forecast agricultural production in the next period. In spite of the importance of forecasting agricultural production, Turkish Statistical Institute (TURKSTAT) is able to make its first forecast in July every year after about $80 \%$ of the crop harvested in Turkey. This is indeed not a forecast. The main motivation of this work is said to be this shortcoming.

The aim of this study is to examine the existence of chaotic structure in agricultural production in Turkey by using "Chaotic Dynamic Analysis (CDA)" and to provide accurate forecasts of agricultural production. The main reason for choosing this method is the assumption that crop production has a chaotic structure. The systems that have chaotic structure cannot be solved by using deterministic linear models. The supply of agricultural products in the next period may be forecasted more accurately by using models suitable for the products' production structure.

The data of wheat, barley and rice production in Turkey was obtained from Turkish Statistical Institute (TURKSTAT) and covers the period of 1991 to 2009. Our analysis shows that the supply of the selected agricultural products has a chaotic structure. The dynamic system that we constructed in this study predicted the supply of year 2010 with a margin error of $0.5 \%, 5 \%$, and $2.5 \%$ for wheat, barley, and rice respectively. These are quite accurate predictions compared to the predictions of the linear models. This study is the first attempt using CDA to forecast future agricultural product supply in Turkey. The findings of this study will help to produce effective policies to prevent supply disequilibrium, and excess price fluctuations in agricultural markets.

The rest of the paper is organized as follows: The next section discuses chaos theory and its application in both economics and agriculture. Construction of the dynamic system and testing for the chaotic structure of the series of the selected agricultural products are presented in section 3. One-year supply predictions of wheat, barley and rice are given in section 4. Prediction of the supply of the selected products in 2010 is provided in section 5. Finally, section 6 concludes.

\section{Chaos: Theory and Literature}

Chaos referred as 'non-scheme' and 'unpredictable situation' is defined as 'irregularity pattern' in science. Perhaps, the most satisfactory definition of chaos concept is the one given by physicist Jensen: "Chaos is irregular and unpredictable behaviour of complex nonlinear dynamic systems" (Gleick, 1997). Chaos represents a stochastic behaviour that is generated by deterministic system (Tsonis, 1992; Medio, 1992). Chaotic series may be expressed as non-linear, dynamic and deterministic series (Brock, 1986). A chaotic system is said to be the system highly sensitive to initial conditions. A very small change in initial conditions may cause system to create very large fluctuations in long term. The dynamics seemed to be random in chaotic system might well be the outcome of a deterministic system (Wei and Leuthold, 1998). In fact, chaos is a phenomenon that can be controlled if it's determined.

Chaos theory may be applied in many branches of science, although it's emerged in the field of science such as mathematics, and physics. The idea that dynamic systems may show chaotic behaviour was first seen in the works of J. H. Poincare's as "three-body problem". In the beginning of the $20^{\text {th }}$ century, Poincare showed that how much a dynamic system depends 
on initial conditions by modelling the solar system in his study. However the recognition of this phenomenon by different disciplines had been in the second half of $20^{\text {th }}$ century. Lorenz (1963), in his model of weather pattern with 12 variables, for example, identified that a very small change in initial conditions could lead to unforeseen different situations.

Chaotic dynamical systems usually have attractors that have been called "strong attractors". Fractal dimension (Minkowski dimension) and correlation dimension of these attractors provide information about the magnitude of the chaotic structure. Intuitively the size of a set should be a natural number, particularly the topological dimension. There are dimensions that the size of a set can only be natural numbers. However, there are sets that characterize the size of these sets with the natural numbers doesn't seem to be realistic. For this reason, all non - negative real numbers may be the size needed. Trailers of fractals and chaotic dynamical systems are often the sets of this type.

A reconstruction of a dynamic system from a time series obtained from a specific system is based on a theorem of Takens (1981). According to this theorem, there are similarities between the original dynamic system and the dynamic system generated. Therefore, it's quite possible to have information about the structure of the original dynamic system by using the dynamic system generated. For example, one can determine whether a system has a chaotic structure by calculating the Lyapunov exponents of system generated by using a time series (Wolf et al., 1985; Eckmann and Ruelle, 1985; Eckmann et al., 1986, Bryant and Brown, 1990; Brown, 1993). Fractal dimension or correlation dimension of the attractors of the reconstructed dynamic system may also provide information about the chaotic structure of original dynamic system (DeGrauwe et al., 1993).

Although long time series are preferred in investigating the chaotic structures of the systems, it's possible to examine the chaos by using relatively short time series (Rosenstein et al., 1993; Sakai et al., 2008). If the generated system is chaotic, then it's possible to make shortterm predictions (Sakai et al., 2008; Casidagli, 1989).

\subsection{Chaotic Approach to Economic Modelling}

The first step in chaotic dynamic approach is to determine the classic 'white noise' or 'chaotic noise'. BDS test proposed by Brock et. al. (1986) is a test developed to check if there is any random or unknown structure in a given time series. This test is very important in determination of whether a series repeats itself in a systematic way or has any random values or not. The problem emerging frequently in economic modelling is the use of deterministic equilibrium models observed mostly in irregular movements of time series and random looking fluctuations. Superiority of nonlinear chaotic models is that they enable us to drive this kind of irregular moments without stochastic variables (Bacsi, 1997).

Establishment of models that have chaotic dynamics is quite simple in economics. Collett and Eckmann (1980) showed that any shifting relation in $x(t+1)$ curve as a function of $x(t)$ is hill-shaped. Moreover, this kind of behaviour may be constructed by using appropriate parameters. The most fundamental problem of the existence of chaos in an economic time series is to model the noise, trend, and general structural changes of the time series. While changes in the structure of series may be modelled by ARCH (autoregressive conditional heteroscedasticity) or GARCH (generalized autoregressive conditional heteroscedasticity) that allows changing mean and variance, modelling the noise and the trend in series is much more difficult. These problems are usually due to lack of sufficient number of observations.

Hinich, BDS, White and Kaplan tests are the tests used in investigating the existence of non-linear structure and chaos in economic variables. Grassberger-Procaccia (GP) Correlation 
Dimension test based on restructuring of phase space is another test used in investigation of the existence of chaotic structure in time series.

The most prominent feature of chaotic systems is being highly sensitive to initial conditions. One way used in determining the sensitive dependence on initial conditions of the system, or the existence of chaotic structure, is the method of Lyapunov exponent (Barnett and Serletis, 2000). Lyapunov exponent measures exponential changes in the mean level of convergence or divergence between paths due to infinitely small differences in initial conditions of series (Barnett and Serletis, 2000). A positive Lyapunov exponent indicates the existence of chaotic behaviour in the series. Therefore, Nychka et al. (1992) proposed a regression method for testing positive dominant Lyapunov exponent. Lyapunov exponent approach, however, used to analyse the existence of chaotic structure in series requires both long time series and more sensitive to dynamic noise (Barnett and Serletis, 2000).

The applications of chaotic approach in economic modelling are observed to be concentrated more in financial markets. There are two reasons for this: First chaotic dynamic analysis methods require long time series. The data on financial markets are quite suitable because one may find hourly, daily and weekly data for financial markets. Secondly, prediction of future price and/or return realizations of estates are very important in these markets.

One of the first studies investigating the existence of chaotic structure of securities is the work of Frank and Stengos (1989) using GP correlation dimension and Kolmogorov entropy for daily, weekly and two weekly returns of silver and gold markets for the period 1974 1986. The study shows that gold and silver yield series have chaotic behaviour, and obtains the result that price changes in securities can be estimated for a short term. Hsieh (1989) in his study describing the nonlinear dependence of five different exchange rate series found that the GARCH model explains a large part of the nonlinear dependence of series. Lee et. al. (1993) found the existence of nonlinear structures in weekly changes of stock exchange market indices of four emerging Asian (Hong Kong, Korea, Singapore, and Taiwan), Japan and US markets. Abhyankar and Copeland (1997) explored whether there is a low dimensional chaotic process in these markets and tested for nonlinear dependence in security markets. They showed the presence of nonlinear structures, but found that these series don't have a low - dimensional chaos.

Harrison et al. (1999), in their study on Standard and Poors' composite index series consisting of 16127 observations between 1928 and 1987, investigated the existence of chaotic structure and found a strong degree of chaos in S\&P 500 series by using the GP correlation dimension test. Serletis (1995) examined the chaotic dynamics of monthly money supply series from 1960 to 1992 by different methods and concluded that money supply series were chaotic in the period examined. In another study investigating the chaotic structure in the series of black market exchange rates of seven Eastern European countries by using the BDS test, NEGM test and Lyapunov exponent approaches, Serletis and Gogas (1997) identified the existence of a chaotic structure in the series of Russian Rouble and East Germany Mark. Panas (2001) tested if there is long-term memory and chaotic structure by price series of six selected metal products in London metal market. In this study correlation dimension, entropy and Lyapunov exponent for the returns of metal products were used in determining the chaotic behaviour. The findings showed that metal price series shows time dependent varying volatility and large skewness and kurtosis (Panas, 2001). That means that the series are not normally distributed and suggests the presence of nonlinear dynamics in these series. 


\subsection{Chaotic Approach to Modelling Supply and Demand of Agricultural Products}

The first dynamic system developed to explain the cycles in agricultural production was perhaps suggested by Cobweb. The Cobweb model was then replaced as Cobweb theorem in the literature of agricultural economics. This model argues that the imbalances between supply and demand of agricultural products leading price fluctuations is the result of supply decision of next period taken based on the current market data in this period. These imbalances in the market for agricultural products that have different elasticity of supply and demand are an inevitable phenomenon.

While there are a number of studies modelling the chaotic structure in price or returns of goods or asset, there are a few studies investigating the chaotic structure in crop production series. Perhaps the first study investigating the chaotic structure of variables in agriculture, crop production or ecological system is May's (1976) discrete logistic model showing the chaotic structure of the ecological system. However, the one - dimensional discrete model derived from ecological data to determine the chaotic behaviour wasn't very successful (Sakai, 2001).

Chavas and Holt (1993), on the other hand, in his study examining the deterministic chaotic structure of pork production found evidence of the existence of chaotic structure by using GP correlation approach. Similarly, Chiarella (1988) found chaotic behaviour in the parameters of Cobweb model used to determine the price dynamics in fully competitive markets. Cromwell and Labys (1993) examined the movements of monthly cocoa, coffee, rice, sugar, tea, and wheat prices between the years of 1960 - 1992 and found nonlinear dependence in the cocoa, tea, and sugar prices by using GARCH $(1,1)$. Moreover, by using the Lyapunov exponent, they showed that wheat price has a chaotic structure. Burton (1993) showed the existence of chaos in the model of agricultural products by using the logistic map.

The Response Surface Methodology (RMS) developed by Turchin and Taylor (1992) has been emerged as a new alternative in determining the chaos in ecological systems. Sakai (2001) determined low dimensional deterministic chaotic structure in a corn production series by using RMS. Similarly, Tilman and Vedin (1993) identified the chaotic surge in grass production. Sakai et al. (2008) examined the chaotic dynamics in the ecological time series with a very few data and found that the system has a chaotic structure. In the same study, they found also that tangerine production exhibit chaotic behaviour.

\section{Chaotic Dynamic Analysis of Selected Agricultural Products and Supply Predictions}

This study argues that the supply of barley, wheat and rice produced in Turkey has a chaotic structure. In order to verify this, we first test if the production of these agricultural products shows a chaotic structure by using Lyapunov exponents calculated by following Sakai et al. (2008). After evaluating the calculated Lyapunov exponents and showing that the series has a chaotic structure, we predict the next year's supply of these products.

The data on the production volumes of the provinces were obtained from Turkish Statistical Institute (TURKSTAT) from 1991 to 2009. Barley, wheat and rice production data are examined separately. While we used provincial data for barley and wheat production, we used regional data for rice production. 
Following Sakai at. al. (2008), let $i$ and $t$ denote province/region and year respectively. The series for wheat and barley may then be written as follows:

$$
x(i, t)
$$

where

$$
\begin{aligned}
& i=\text { Adana, Adiyaman, ................., Zonguldak. } \\
& t=1991, \ldots \ldots \ldots \ldots, 2009 .
\end{aligned}
$$

Regional time series for rice is constructed in a similar approach;

$$
x(i, t)
$$

where

$$
\begin{aligned}
i & =\text { Region } 1, \text { Region } 2, \ldots \ldots \ldots \ldots \ldots \ldots . ., \text { Region } 6 . \\
t & =1991, \ldots \ldots \ldots \ldots, 2009 .
\end{aligned}
$$

The points of three-dimensional space $\left(R^{3}\right)$ are obtained from provincial time series of each product over the years, $t=1993,1994, \ldots, 2009$ and denoted by;

$$
X(i, t)=(x(i, t), x(i, t-1), x(i, t-2))
$$

In other words, the time series are embedded to $R^{3}$. A dynamic is defined in $R^{3}$ by setting the next period value of any $X(i, t)$ to the point $X(i, t+1)$. To determine whether the system has a chaotic structure, after selecting a point $X(i, t)$, the neighbouring points were determined. The same calculations were repeated by changing the neighbouring points from 4 to 12 . The $k$ points near to the point $X(i, t)$ are shown as:

$$
Y(i, t, p), \text { where } p=1,2, \ldots \ldots ., k \text {. }
$$

If the distance between $Y(i, t, p)$ and $X(i, t)$ is $D(i, t, p)$, then the point $V(i, t)$ representing points sufficiently near to the $X(i, t)$ may be formulated as follows:

$$
V(i, t)={ }_{p=1}^{k} Y(i, t, p) \frac{D(i, t, p)}{{ }_{q=1}^{k} D(i, t, q)}
$$

One-step evolution of $V(i, t)$, i.e. $U(i, t)$, may be written as the distance-weighted average of $Y(i, t+1, p)$ :

$$
U(i, t)={ }_{p=1}^{k} Y(i, t+1, p) \frac{(D(i, t, p))}{{ }_{q=1}^{k} D(i, t, q)}
$$

To determine the Jacobian matrix around $V(i, t)$, again $k$ points near to the point $V(i, t)$ are determined in $R^{3}$. These points are defined as $R(i, t, p)$, where $p=1,2, \ldots . . k$. Let the difference between $R(i, t, p), p=1,2, \ldots . . k$ and $V(i, t)$ be;

$$
y(i, t, p)=R(i, t, p)-V(i, t)
$$
follows:

and the difference vector between value of $R(i, t+1, p)$ and $U(i, t)$ may be written as

$$
z(i, t, p)=R(i, t+1, p) \quad U(i, t) .
$$


If the Jacobian matrix around $V(i, t)$ is $G(i, t)$, then it should be

$$
z(i, t, p) \quad G(i, t) y(i, t, p) \quad p=1,2, \ldots, k
$$

In order to determine whether the time series of the supply of barley, wheat and rice have chaotic structure, Oseledec eigenvalues of the matrix is calculated by taking time shift for one year as follows:

$$
O(i, t)=\left[G(i, t) G(i, t)^{T}\right]^{\frac{1}{2}} .
$$

The eigenvalues at the point $V(i, t)$ are the local Lyapunov exponents. Finally, the existence of positive eigenvalues (positive Lyapunov exponents) is the indicator of being chaotic.

The chaotic structure of barley, wheat and rice production in Turkey is determined by considering Lyapunov exponents. Three-dimensional dynamical systems for each product are separately built from the data between 1991 and 2008. Thus, the system will have 3 different Lyapunov exponents. However, existence of one positive Lyapunov exponent in the system is sufficient in determining the chaos.

In generating Jacobian matrix, different neighbouring points from 3 to 12 are used. In each case, it is found that one of the Lyapunov exponents of cities or regions is always positive, one is around zero and the other is negative.

Lyapunov exponents obtained for each product are given in Table 1. The table shows that Lyapunov exponents vary between 1.17 and 1.48 for barley, 1.1 and 1.58 for wheat, and 0.58 and 1.42 for rice provincial or regional data and are all positive for each product. This finding clearly implies that wheat, barley, and rice production in Turkey have a chaotic structure.

Table 1. Lyapunov exponents for Turkey

\begin{tabular}{lrrr}
\hline Year & Barley & Wheat & Rice \\
\hline $\mathbf{1 9 9 3}$ & 1.37 & 1.39 & 1.01 \\
$\mathbf{1 9 9 4}$ & 1.36 & 1.43 & 1.01 \\
$\mathbf{1 9 9 5}$ & 1.30 & 1.44 & 0.97 \\
$\mathbf{1 9 9 6}$ & 1.42 & 1.31 & 0.96 \\
$\mathbf{1 9 9 7}$ & 1.46 & 1.58 & 1.30 \\
$\mathbf{1 9 9 8}$ & 1.48 & 1.38 & 0.84 \\
$\mathbf{1 9 9 9}$ & 1.25 & 1.47 & 1.11 \\
$\mathbf{2 0 0 0}$ & 1.36 & 1.37 & 0.83 \\
$\mathbf{2 0 0 1}$ & 1.20 & 1.24 & 0.58 \\
$\mathbf{2 0 0 2}$ & 1.19 & 1.15 & 0.67 \\
$\mathbf{2 0 0 3}$ & 1.30 & 1.38 & 1.20 \\
$\mathbf{2 0 0 4}$ & 1.32 & 1.27 & 1.15 \\
$\mathbf{2 0 0 5}$ & 1.29 & 1.24 & 1.42 \\
$\mathbf{2 0 0 6}$ & 1.43 & 1.46 & 1.04 \\
$\mathbf{2 0 0 7}$ & 1.39 & 1.38 & 0.92 \\
$\mathbf{2 0 0 8}$ & 1.17 & 1.10 & 0.73 \\
\hline $\mathbf{S 0 u r}$ & Cal
\end{tabular}

Source: Calculated by the authors using the data TURKSTAT (2010) data. 


\section{Annual Supply Predictions of the Selected Products}

The next year value of production of barley, wheat and rice is predicted as follows: Let $\hat{X}(i, t+1)$ denote the next year predicted value of the product that is obtained from the point $X(i, t)=\left(x(i, t), x\left(\begin{array}{ll}i, t & 1\end{array}\right), x(i, t \quad 2)\right)$. The predicted value may be written as follows:

$$
\hat{X}(i, t+1)=U(i, t)+G(i, t)(X(i, t) \quad V(i, t))
$$

Thus, the predicted supply of the product is equal to the first component of predicted production. The estimate of Turkey's total production is obtained by summing the provincial/regional predictions.

Annual supply predictions of barley, wheat and rice are obtained for neighbouring points 5 and 6 . The most accurate results in most cases were obtained for the neighbouring point 5 .

Production predictions of barley for five and six neighbouring points and the actual production values are given in Figure 1-2. Predicted values from the year 1994 to 2004 are quite close to the values of the actual production of barley. The predicted value of the year 2000 and 2004 were obtained with a zero percentage error. However, the actual production is underestimated between the years 1995-1999 and over predicted between the years 20012004. The average prediction error for barley is about 0.6 percentage points.

The barley production has not been predicted exactly during the analysis period for neighbouring point 6 . Predicted values are very close to the actual ones in the years 2000, 2001, 2002 and 2006. The ratio of error is 2 percent for the years 2000, 2001 and 2002, while the deviation turned out to be 1 percent for the year 2006. The largest deviations of predicted from actual values realized in 2007 and 2008. Prediction error is 16\% in 2007 and 23\% in 2008. Percentage of prediction error of neighbouring point 6 prediction is about 2 percent.

\section{Figure 1: Barley 5 Point Predictions}

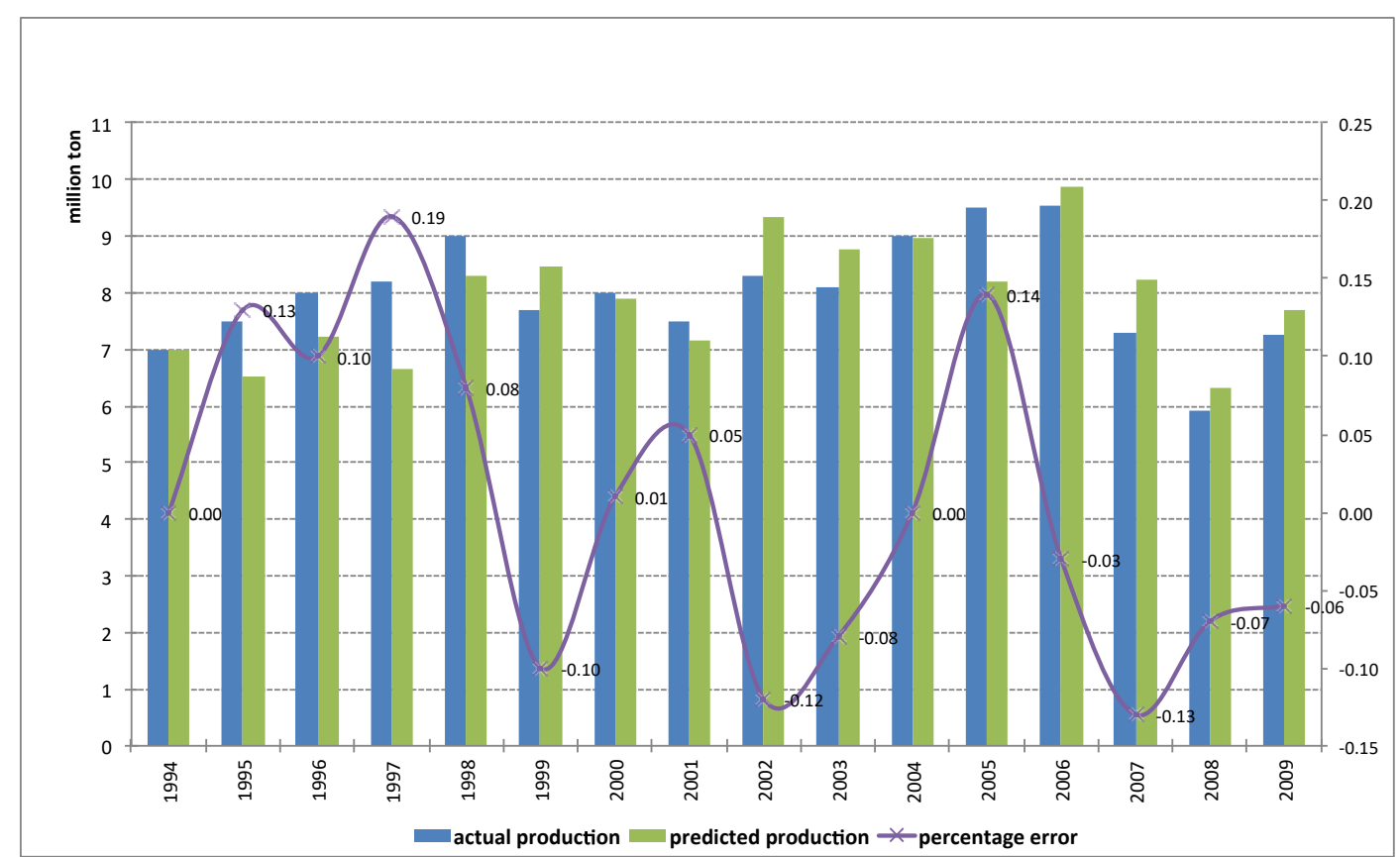

Source: Calculated by the authors.

Note: Right axis is the percentage error. 
Figure 2: Barley 6 Point Predictions

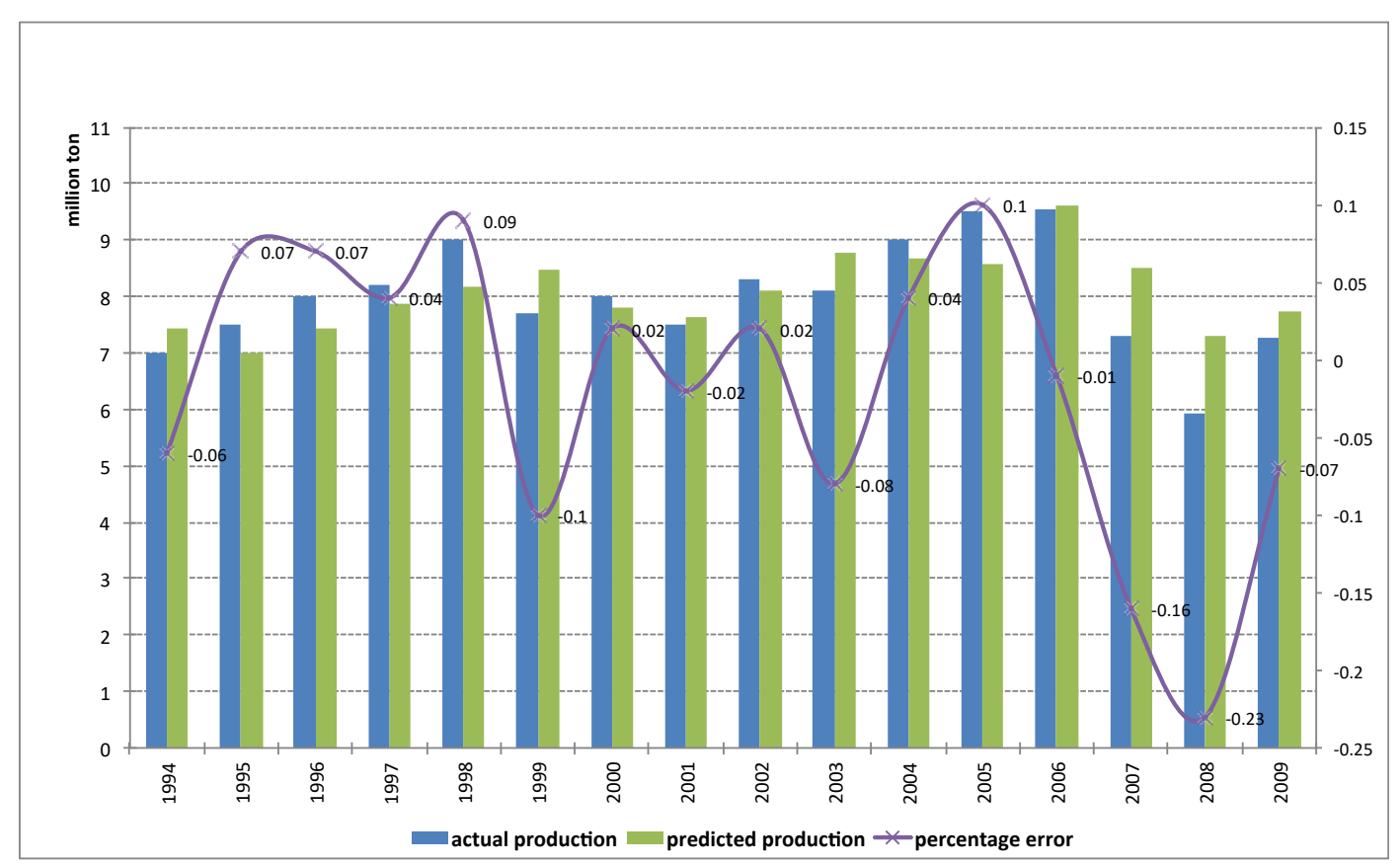

Source: Calculated by the authors.

Note: Right axis is the percentage error.

Wheat production prediction for five and six neighbouring points together with the actual production values are shown in Figure 3-4. The closest results to the actual production value are obtained for the years 1997 and 2002. The prediction error in these years came out to be 1 percentage point. Wheat production has not been precisely predicted during the analysis period. Prediction error is the highest in years 2009 and 2007, with 14 and 15 percentage points respectively. Average error of predictions is obtained as 1 percent in the period analysed.

Actual and predicted production for six neighbouring point for wheat are found to be the same in the year 2002. The highest margin of error was in the year 2006 with 16 percent. The error percentage of average of predicted values is 1 percent in the analysis period. The results on the wheat production, shows that the neighbouring 5 point predictions were better than the neighbouring 6 point predictions.

The rice production is predicted for 6 different region of Turkey since rice is not produced in every province of Turkey. These regions are as follows:

$1^{\text {st }}$ region: Edirne, İstanbul, Kırklareli, Tekirdağ

$2^{\text {nd }}$ region: Balıkesir, Bursa, Çanakkale, İzmir

$3^{\text {rd }}$ region: Ankara, Bolu, Çankırı, Eskişehir, Zonguldak, Kırıkkale, Karabük, Düzce

$4^{\text {th }}$ region: Amasya, Çorum, Kastamonu, Samsun, Sinop, Tokat

$5^{\text {th }}$ region: Adana, Antalya, Gaziantep, Hatay, Mersin, Kahramanmaraş, Osmaniye

$6^{\text {th }}$ region: Adıyaman, Artvin, Bingöl, Bitlis, Diyarbakır, Elazığ, Erzurum, Hakkâri,

Malatya, Mardin, Siirt, Şanlıurfa, Batman, Şırnak, Iğdır. 


\section{Figure 3: Wheat 5 Point Predictions}

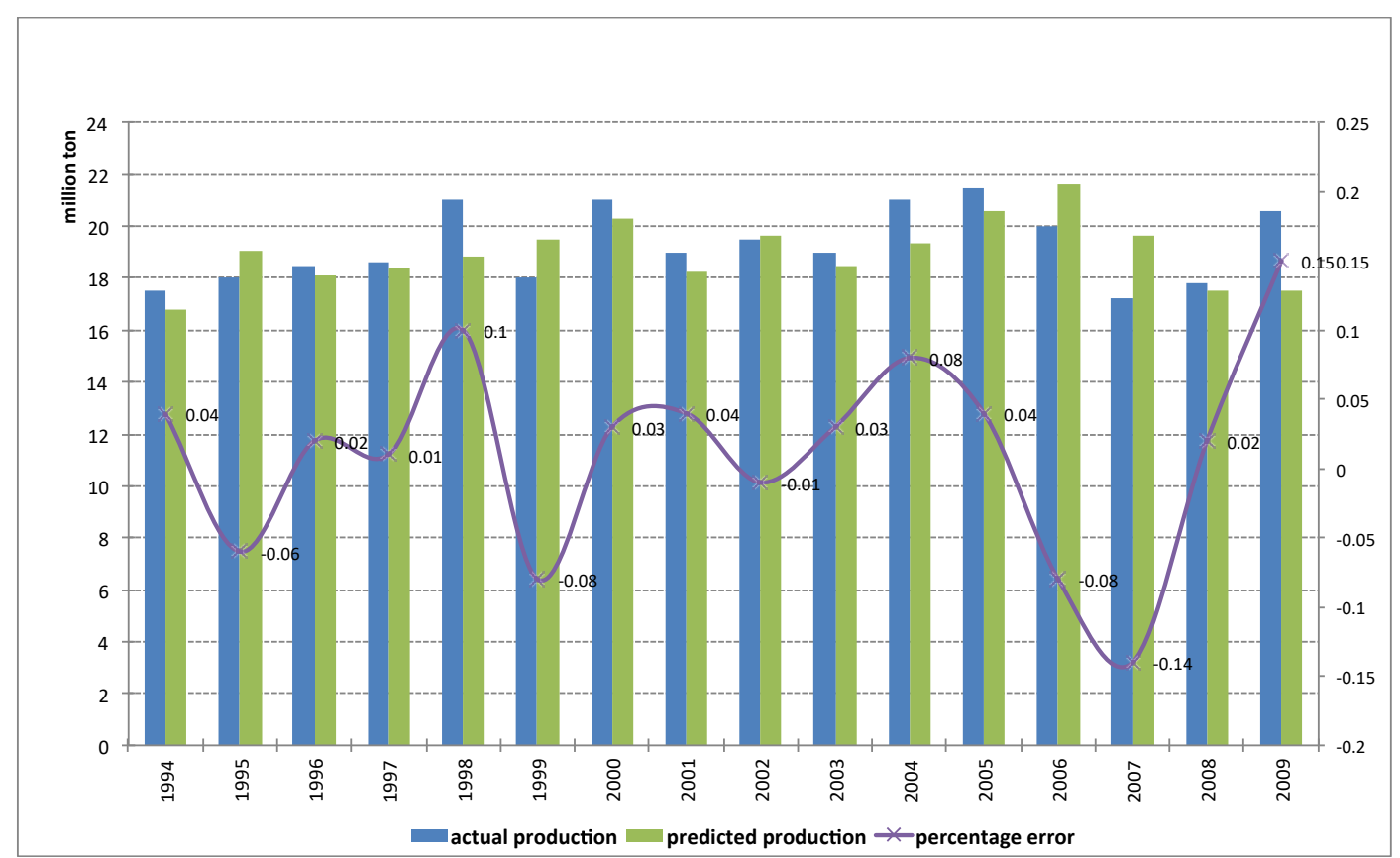

Source: Calculated by the authors.

Note: Right axis is the percentage error.

Figure 4. Wheat 6 Point Predictions

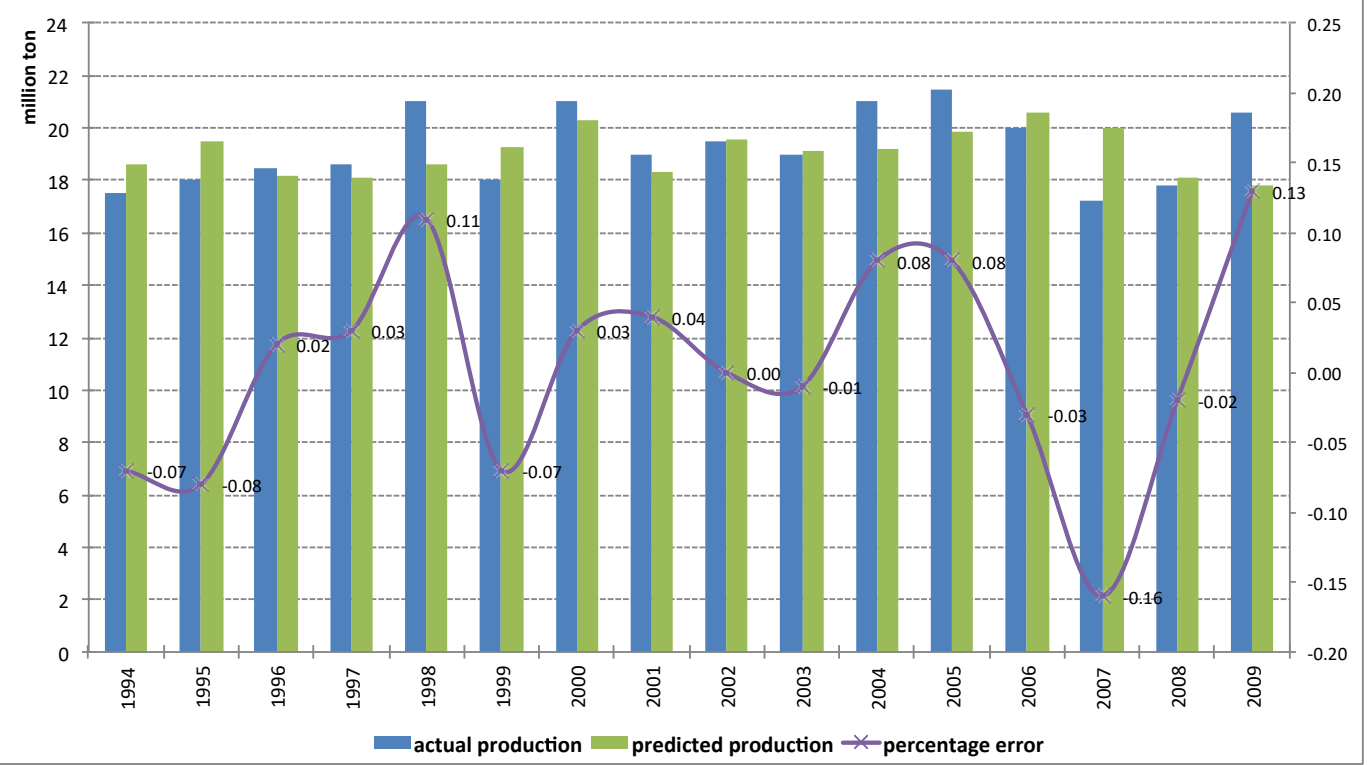

Source: Calculated by the authors.

Note: Right axis is the percentage error.

Actual and 5 and 6 neighbouring points predictions of rice production in Turkey is given in Figure 5 and 6 . Our predictions show that the actual and neighbouring 5 and 6 points predictions of rice production in the years 1995, 1999 and 2001 are equal. In fact, form 1995 to 2003 we had very accurate predictions in both 5 and 6 neighbouring points. The best results for neighbouring point 6 predictions are obtained in 1995 and 2001 with a prediction error of 1 percent. However, the deviation of prediction form actual value increases after 2004. The 
highest deviation of predicted value from actual value in rice production is realized in year 2005. The error is about 55 percent in this year.

Figure 5: Rice 5 Point Predictions

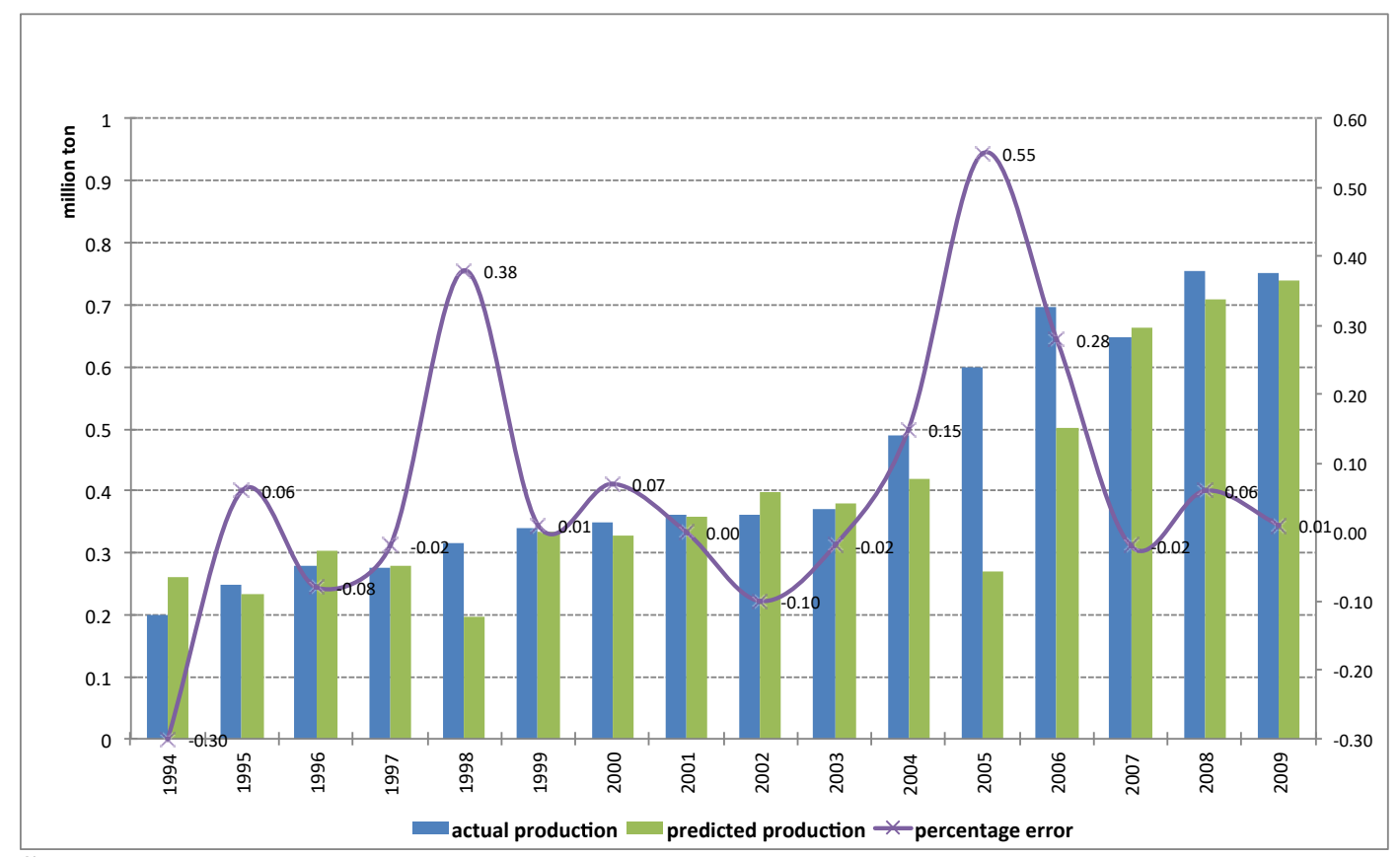

Source: Calculated by the authors.

Note: Right axis is the percentage error.

\section{Figure 6: Rice 6 Point Predictions}

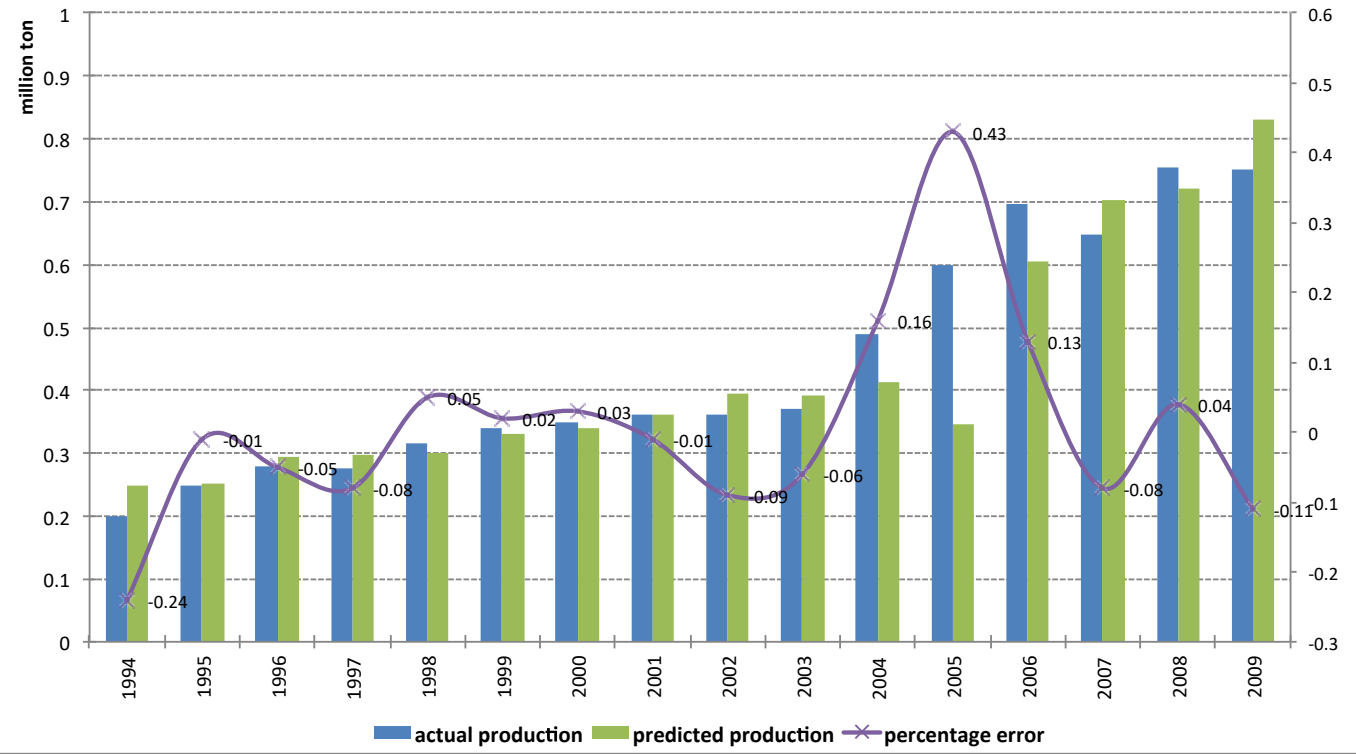

Source: Calculated by the authors.

Note: Right axis is the percentage error. 


\section{Supply Predictions of Selected Products in 2010}

The predicted values of production of barley, wheat, and rice in 2010 were obtained by using the data of $1991-2009$. The values of the actual production quantities are obtained from TURKSTAT's bulletin 'Crop Production (Final Results)' published on March 25 of 2011.

Actual production in 2010 and predicted productions (neighbouring 4, 5 and 6 points) are shown in Figure 7. The amount of actual barley production in 2010 was 7.2 million tons. The amount of barley production was predicted as 8.9 million tons obtained with estimate of the neighbouring point 4 . Neighbouring 5 and 6 points predictions were found to be 9 and 7.5 million tons, respectively. The best prediction for barley production is obtained with neighbouring 6 point estimate in 2010 with 5 percentage point error.

Figure 7: Predictions of barley production in 2010

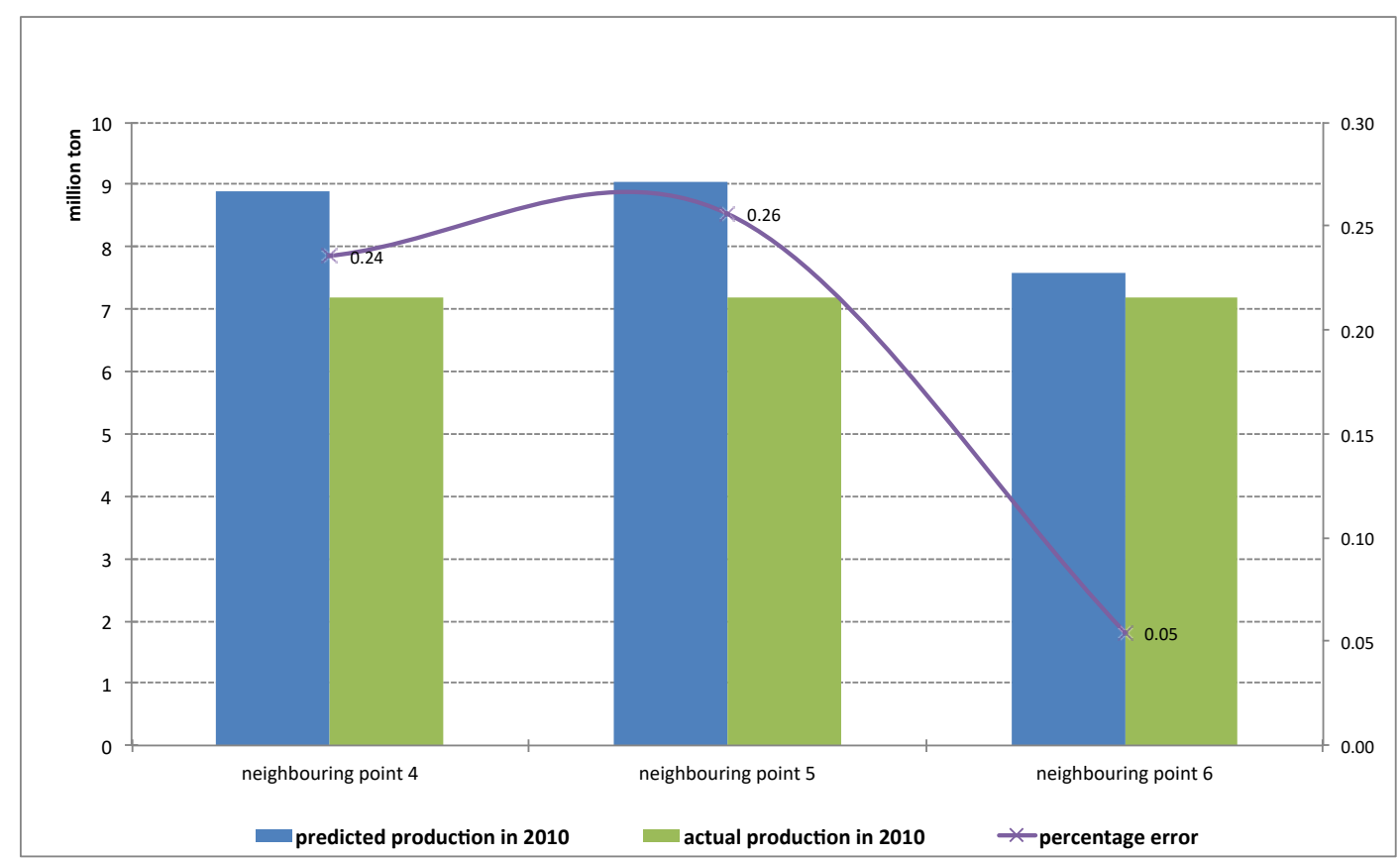

Source: Actual production data in 2010 is obtained from TURKSTAT 2011 Bulletin.

Note: Right axis is the percentage error.

The amount of actual wheat production in 2010 was 19.6 million tons (see Figure 8). We predicted the year 2010 production of wheat as 18.4 million tons obtained with estimate of the neighbouring point 4 . Neighbouring 5 and 6 points estimates turned out to be even better. The predictions were 19.2 and 19.5 million tons. The best estimate for wheat production in 2010 was the neighbouring point 6 prediction with 0.5 percent error.

Actual and predicted values of rice production in 2010 are presented in figure 9. The amount of actual rice production in 2010 was 860 thousand tons. The 4, 5, and 6 neighbouring point predictions of rice production were found to be 985,838 , and 780 thousand tons. The best estimate for rice production in 2010 was the neighbouring point 5 estimate with 2.5 percent error. 
Figure 8: Predictions of wheat production in 2010

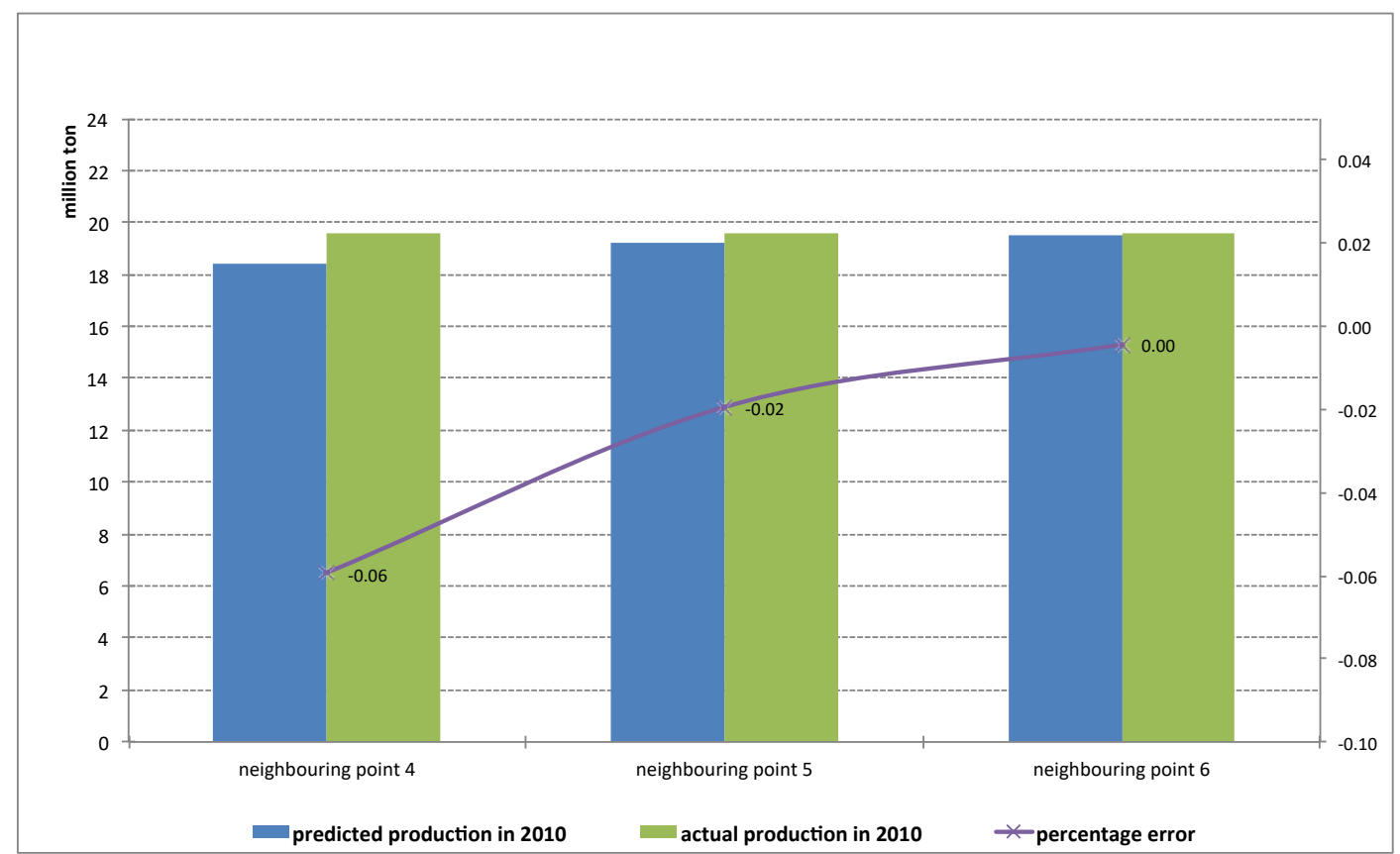

Source: Actual production data in 2010 is obtained from TURKSTAT 2011 Bulletin.

Note: Right axis is the percentage error.

\section{Figure 9: Predictions of rice production in 2010}

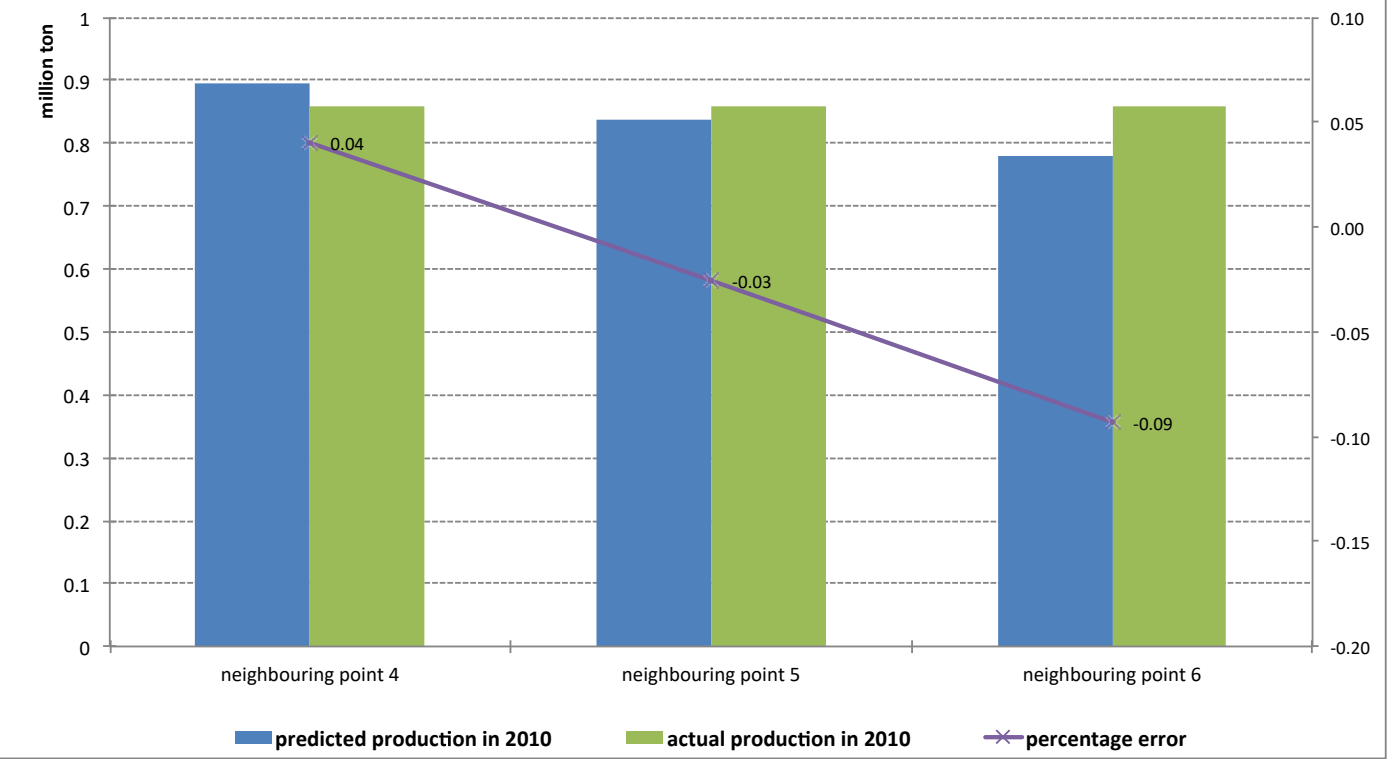

Source: Actual production data in 2010 is obtained from TURKSTAT 2011 Bulletin.

Note: Right axis is the percentage error.

\section{Conclusion}

This study examines the existence of chaotic structure in the supply of wheat, barley and rice production in Turkey by using "Chaotic Dynamic Analysis (CDA)" and provides an alternative model of forecasting for agricultural production. We argue that the systems exhibiting chaotic structure cannot be solved by using deterministic linear models. This study, 
therefore, proposes a new model of forecasting by using chaotic approach for agricultural production.

Our analysis based on the data of wheat, barley and rice production in Turkey obtained from Turkish Statistical Institute (TURKSTAT) shows first that the supply of the selected agricultural products have a chaotic structure. Our dynamic system constructed predicted the yearly production of barley and wheat in Turkey quite accurately from 1994 to 2009 . We predicted the supply of year 2010 production with 0.5 percentage error for wheat, 5 percentage error for barley, and 2.5 percentage error for rice. This study is the first attempt using CDA to forecast future agricultural product supply in Turkey.

This study, by proposing a new model of predication of the future values of agricultural supply, will help to produce effective policies to prevent supply disequilibrium, and excess price fluctuations.

\section{References}

Abhyankar, A., \& Copeland L.S. (1997). Uncovering nonlinear structure in real-time stock market indices: The S\&P 500, The DAX, The NIKKEI 225 and The FTSE 100. Journal of Business and Economic Statistics, 15(1), 1-14. doi:10.1080/ 07350015. 1997.10524681

Bacsi, Z. (1997). Modelling chaotic behaviour in agricultural prices using a discrete deterministic nonlinear price model. Agricultural Systems, 55(3), 445-459. doi:10.1016/S0308$\underline{521 X(97) 00003-6}$

Barnett, W.A., \& Serletis, A. (2000). Martingales, nonlinearity and chaos. Journal of Economics Dynamics and Control, 24, 703-724. doi:10.1016/S0165-1889(99)00023-8

Birkhauser, B., Cromwell, J.B., \& Labys, W.C. (1993). Testing for Nonlinear Dynamics and Chaos in Agricultural Commodity Prices. Institute for Labor Study, West Virginia University.

Brown, R. (1993). Calculating lyapunov exponents for short and/or noisy data sets. Physical. Review $E$, 47(6), 3962-3969. doi:10.1103/PhysRevE.47.3962

Brock, W. A., 1986. Distinguishing random and deterministic systems: abridged version. Journal of Economic Theory, 40(1), 168-195. doi:10.1016/0022-0531(86)90014-1

Brock, W.A., Dechert, W., \& Schienkman, J. A. (1986). Test for independence based on the correlation dimension. Working Paper, University of Wisconsin at Madison and University of Chicago.

Bryant, P., \& Brown, R. (1990). Lyapunov Exponents from Observed Time Series. Physical Review Letters, 65(13), 1523-1526. doi:10.1103/PhysRevLett.65.1523

Burton, M. (1993). Some illustrations of chaos in commodity models. Journal of Agricultural Economics, 44(1), 38-50. doi:10.1111/j.1477-9552.1993.tb00249.x

Casdagli, M. (1989). Nonlinear prediction of chaotic time series. Physica D: Nonlinear Phenomena, 35(3), 335-356. doi:10.1016/0167-2789(89)90074-2

Chavas, J. P., \& Holt, M. T. (1993). Market instability and nonlinear dynamics. American Journal of Agricultural Economics, 75(1), 113-120. doi:10.2307/1242959

Chiarella, C. (1988). The cobweb model, its instability and the onset of chaos. Economic Modelling, 5(4), 376-384. doi:10.1016/0264-9993(88)90010-7

Collett, P., \& Eckmann, J. P. (1980). Iterated Maps on the Interval as Dynamical Systems.

Çetin, N. (1994). EEG'de Kaotik Boyut. Unpublished Ph.D. Thesis Eskişehir: Anadolu University, Institute of Natural Sciences. 
Demir, B. (1999). Dinamik Sistemler ve Nöron Siklusları, Unpublished Ph.D. Thesis. Eskişehir: Anadolu University, Institute of Natural Sciences.

Degrauwe, P., Dewachter, H., \& Embrechts, M. (1993). Exchange Rate Theory, Chaotic Models of Foreign Exchange Markets. London: Blackwell Publishers.

Eckmann, J. P., \& Ruelle, D. (1985). Ergodic theory of chaos and strange attractors. Reviews of. Modern Physics, 57(3), 617-656. doi:10.1103/RevModPhys.57.617

Eckmann, J. P., Kamphorst, S. O., Ruelle, D., \& Ciliberto, S. (1986). Liapunov exponents from time series. Physical Review A, 34(6), 4971-4979. doi:10.1103/PhysRevA.34.4971

Frank, M., \& Stengos, T. (1989). Measuring the strangeness of gold and silver rates of return. Review of Economic Studies. 56(4), 553-567. doi:10.2307/2297500

Gleick, J., 1997. Chaos: Making a New Science, Vintage, London.

Harrison, R., Yu, D., Oxley, L., Lu, W., \& Donald, G. (1999). Non-linear noise reduction and detecting chaos: some evidence from the S\&P composite price index. Mathematics and Computers in Simulation, 48, 497-502. doi:10.1016/S0378-4754(99)00029-4

Hsieh, D. (1989). Testing for nonlinear dependence in daily foreign exchange rates. The Journal of Business, 62(3), 339-368. doi:10.1086/296466

Lee, I. S., Sewell, S.P., \& S.R. Stansell. (1993). Nonlinearities in emerging foreign capital markets. Journal of Business Finance and Accounting, 20(2), 237-248. doi:10.1111/j.1468$\underline{\text { 5957.1993.tb00662.x }}$

Lorenz, E. (1963). Deterministic nonperiodic flow. Journal of Atmospheric Sciences, 20(2), 130-140. doi:10.1175/1520-0469(1963)020<0130:DNF>2.0.CO;2

May, R. (1976). Simple mathematical models with very complicated dynamics. Nature, 261, 459467. doi:10.1007/978-0-387-21830-4_7

Medio, A. (1992). Chaotic Dynamics: Theory and Applications to Economics. Cambridge University Press.

Nychka, D., Ellner, S., Gallant, R., \& McCalrey, D. (1992). Finding chaos in noisy systems. Journal of the Royal Statistical Society B, 54(2), 399-426.

Panas, E. (2001). Long memory and chaotic models of prices on the London Metal Exchange. Resources Policy, 27, 235-246. doi:10.1016/S0301-4207(02)00008-9

Rosenstin, M. T., Collins, J. J., \& De Luca, C. JA. (1993). Practical Method for Calculating Largest Lyapunov Exponents from Small Data Sets. Physica D: Nonlinear Phenomena, 65, 117-134. doi:10.1016/0167-2789(93)90009-P

Sakai, K. (2001). Nonlinear Dynamics and Chaos in Agricultural Systems. Netherlands: Elsevier.

Sakai, K., Noguchi, Y., \& Asada, S. (2008). Detecting chaos in a citrus orchard: reconstruction of nonlinear dynamics from very short ecological time series. Chaos, Solitons and Fractals, 38(5), 1274-1282. doi:10.1016/j.chaos.2007.01.144

Serletis, A. (1995). Random Walks, Breaking Trend Functions and the Chaotic Structure of the Velocity of the Money. Journal of Business and Economic Statistics, 13(4), 453-458. doi:10.1080/07350015.1995.10524619

Serletis, A., \& Gogas, P. (1997). Chaos in East European black market Exchange rates. Research in Economics, 51(4), 359-385. doi:10.1006/reec.1997.0050

Takens, F. (1981). Detecting Strange Attractors in Turbulance. in. Rand DA, Young LS (eds.) Dynamical Systems and Turbulance, Warwick 1980, Springer Verlag: Lecture Notes in Mathematics, 898. 
Tilman, D., \& Vedin, D. (1993). Oscillation and in the dynamics of a perennial grass. Nature, 353, 653-655. doi:10.1038/353653a0

Tsonis, A. A. (1992). Chaos: From Theory to Applications. New York and London: Plenum Press. doi:10.1007/978-1-4615-3360-3

TURKSTAT, (2010). Tahıllar ve Diğer Bitkisel Ürünler, Tarım İstatistikleri. Ankara: Türkiye İstatistik Kurumu.

Turchin, P., \& Taylor, A.D. (1992). Complex dynamics in ecological time series. Ecology, 73(1), 289-305. doi:10.2307/1938740

Wei, A., \& Leuthold, R. M. (1998). Long agricultural futures prices. ARCH, Long Memory Chaos Processes, OFOR Paper Number 98(03) doi:10.2139/ssrn.126951

Wolf, A., Swift, J. B., Swinney, H. L., \& Vastano, J. A. (1985). Determining lyapunov exponents from a time series. Physica D: Nonlinear Phenomena, 16(3), 285-317. doi:10.1016/0167$\underline{\text { 2789(85)90011-9 }}$ 